\title{
Committee report: Considerations and recommendations for national guidance regarding the retention and use of residual dried blood spot specimens after newborn screening
}

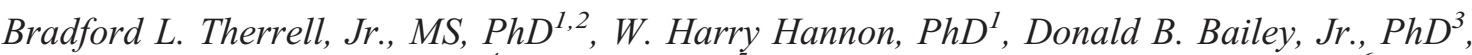 \\ Edward B. Goldman, JD ${ }^{4}$, Jana Monaco ${ }^{5}$, Bent Norgaard-Pedersen, MD, DMSc ${ }^{6}$, \\ Sharon F. Terry, $M A^{5,7}$, Alissa Johnson, $M A^{8}$, and R. Rodney Howell, $M D^{5}$
}

\begin{abstract}
Newborn screening programs are state based with variable policies. Guidance regarding the retention, storage, and use of portions of newborn screening dried blood spots that remain after screening (residual specimens) was first published in 1996. Since then, newborn screening programs have paid increased attention to specimen storage and usage issues. Standard residual specimen uses include quality assurance and program evaluation, treatment efficacy, test refinement, and result verification. In all cases, privacy and security are primary concerns. In general, two distinct state practices regarding the storage and use of residual newborn screening specimens exist: (1) short-term storage ( $<3$ years), primarily for standard program uses and (2) long-term storage ( $>18$ years), for standard program uses and possible important public health research uses. Recently, there have been concerns in some consumer communities regarding both the potential uses of residual specimens and patient (newborn and family) privacy. To assist in policy improvements that can protect the individual's privacy and allow for important public health uses of residual newborn screening specimens, the Secretary of Health and Human Services' Advisory Committee on Heritable Disorders in Newborns and Children has developed recommendations (with requested action by the Secretary where applicable). This report presents the Committee's recommendations and reviews the pertinent associated issues. Genet Med 2011: 13(7):621-624.
\end{abstract}

Key Words: newborn, blood spots, policy, screening, specimen repositories

\footnotetext{
From the ${ }^{1}$ National Newborn Screening and Genetics Resource Center, Austin, Texas; ${ }^{2}$ Department of Pediatrics, University of Texas Health Science Center at San Antonio, San Antonio, Texas; ${ }^{3}$ RTI International, Research Triangle Park, North Carolina; ${ }^{4}$ Department of Obstetrics and Gynecology, University of Michigan, Ann Arbor, Michigan; ${ }^{5}$ SACHDNC; ${ }^{6}$ Department of Clinical Biochemistry and Immunology, Statens Serum Institut, Denmark; ${ }^{7}$ Genetic Alliance, Washington D.C.; and ${ }^{8}$ Johnson Policy Consulting, Annandale, Virginia.
}

W. Harry Hannon, PhD, NNSGRC, 4929 Duncans Lake Point, Buford, GA 30519. E-mail: whannon@bellsouth.net.

The extended version of this article is available as Supplemental Digital Content 1, http://links.lww.com/GIM/A168.

Disclosure: The authors declare no conflict of interest.

Supplemental digital content is available for this article. Direct URL citations appear in the printed text and are provided in the HTML and PDF versions of this article on the journal's Web site (www.geneticsinmedicine.org).

Submitted for publication January 5, 2011

Accepted for publication February 7, 2011

DOI: 10.1097/GIM.0b013e3182147639
$\mathrm{N}$ ewborn screening (NBS) is a highly successful public health program that identifies inherited genetic and other congenital disorders that can cause functional problems and seeks to ensure early follow-up and management for those affected. All states require NBS. State public health agencies are responsible for oversight and implementation of their respective NBS activities. State NBS policies are usually developed with input from multidisciplinary advisory committees that include consumers, ${ }^{1}$ healthcare and public health professionals, and other stakeholders. Although state administration of NBS programs fosters local control and accountability, it also gives rise to variations in practice, including disparate policies on the retention and use of dried blood spot specimens after NBS. Given the potential to advance science and clinical care for newborns, children, their families, and society, the Secretary of Health and Human Services' (HHS) Advisory Committee on Heritable Disorders in Newborns and Children (SACHDNC) calls on policymakers, the public health community, healthcare providers, and families to work together to protect these valuable resources for the public good.

Issues and policies concerning the storage and use of NBS dried blood spots after completion of laboratory testing are not new. Heightened public awareness and continuing emphasis on national discussions and recommendations to guide state-based NBS programs on these issues have led to actions by the SACHDNC. The Committee began investigating the storage and use of residual blood spots in February 2009, and a writing group was approved to develop a white paper for their September 2009 meeting. An executive summary of the paper was distributed for public comment, including three webinars hosted by the Association of Public Health Laboratories (220 participants from 49 states); the National Coordinating Center for the Regional Genetics Collaboratives (38 participants); and the Genetic Alliance (106 participants). Subsequently, public input was combined with Committee and stakeholder comments and incorporated into the paper. A formal request for public comment was published in the Federal Register on April 26, 2010. ${ }^{2}$ During this public comment period, SACHDNC encouraged the Institute of Medicine to convene a public forum on the use and storage of residual specimens for translational research. ${ }^{3}$ The final report recommendations were developed based on input from approximately 550 individuals, 13 organizations, and the Committee, and it was approved for submission to the Secretary of HHS. A letter describing the process and outlining the SACHDNC recommendations was sent to Secretary Sebelius on October $13,2010 .{ }^{4}$ The final report discusses both the underlying issues and SACHDNC recommendations and was prepared as a means of documenting all aspects of SACHDNC activities on this subject. 
This report has two principal purposes. The first is to review the issues facing state NBS programs related to the retention and use of residual dried blood spot specimens. The second is to lay the foundation for developing national guidance in this area. The SACHDNC encourages an approach to guidance that maintains the standard uses of the residual blood specimens and upholds the core principles of benefiting newborns, families, and society. NBS programs must protect privacy and confidentiality and ensure the public's trust while recognizing the potential research value of residual NBS specimens for advancing science and clinical care. The recommendations related to the retention and use of residual dried blood spot specimens are intended to work in concert with-and not to weaken-longstanding and highly effective state NBS programs. Successful NBS must remain the prime objective of these public health programs.

\section{RECOMMENDATIONS}

The SACHDNC has made the following recommendations to the Secretary, HHS regarding storage and use of residual dried blood spots after completion of NBS, and action by the Secretary has been requested where applicable. The SACHDNC recommendations have not been adopted by the Secretary, HHS. The SACHDNC report was referred by the Secretary to her Interagency Coordinating Committee on Newborn and Child Screening (ICC) for their review. The Secretary requested a report from the ICC by June 2012.

All state NBS programs should have a policy in place that has been reviewed by the state attorney general or other appropriate legal authority that specifies who may access and use dried blood specimens once they arrive at the state-designated NBS laboratory, including further access after NBS tests are completed.

All US NBS programs obtain dried blood specimens on an approved filter paper collection device. ${ }^{5}$ These specimens are collected on nearly all of the more than 4 million babies born in the country annually. NBS programs generally retain the unused portions of these specimens (residual specimens) in a secure location for some period after testing is complete. The primary justification for retaining residual specimens is to document that a specimen was collected, received, and properly analyzed.

State NBS programs are charged with being responsible stewards of these specimens-stewardship is defined as the caretaking responsibility in which responsibilities and policies are clearly defined to ensure appropriate uses of NBS specimens. It is understood that the public has a right to expect that specimens are cared for in a manner that protects personal information and eliminates misuse and mistrust. As a result, state public health departments strive to exercise the highest care in receiving, storing, and protecting residual NBS specimens from unauthorized use. The potential research value of residual NBS specimens has increased the need for national harmonization of specimen storage and specimen access policies for both ethical and legal reasons. Identifying a standard set of key issues to be addressed in a comprehensive policy regarding access and use of residual NBS specimens, regardless of the approach, should facilitate greater uniformity among state programs. Multidisciplinary input, including from consumers, should be solicited and thoughtfully considered in developing such a policy. The public should have easy access to information describing the state NBS residual specimen access and use policy.

All state NBS programs should have a policy in place that has been reviewed by the state attorney general or other appropriate legal authority addressing the disposition of dried blood specimens remaining after NBS. Policymakers should consider the value of the specimens as a promising resource for research, the importance of protecting the privacy and confidentiality of families, and the necessity of ensuring the public's trust.

State processes for residual NBS specimen storage should strive to secure the specimens, protect the privacy of the newborn and their families, and promote public trust. State policies also should emphasize transparency of administrative practices and create supporting information that encourages informed public participation. With increased public awareness of stored residual NBS specimens, concerns have emerged that personal medical information such as disease susceptibility might be revealed from these specimens through current and future technological advances. ${ }^{6}$ Concerns focus on possible discrimination, psychological harm, identification of paternity, and social injustices. ${ }^{7}$ However, there are no documented cases of harm resulting from the use of residual NBS specimens. In addition to the federal privacy laws and state policies specific to the storage and use of NBS specimens, state genetic privacy laws, other broader state health privacy laws and regulations, and medical standards of practice may affect the storage and use of residual NBS specimens. ${ }^{8-10}$

Any NBS specimen disposition policy should take into account the standard program uses (program evaluation and quality assurance, treatment efficacy, test refinement, and result verification activities for the laboratory and program) after NBS laboratory testing. The specimen disposition policy also should include the storage conditions and length of time for which specimens will be stored, in concurrence with NCCLS/CLSI Standard LA4-A5 or its current edition. ${ }^{5}$ Linkages of data to personally identifiable information should be carefully addressed, and privacy and confidentiality should be ensured. Parties responsible for drafting the policy should consider whether consent or dissent from families is necessary for uses (such as research) other than NBS laboratory testing and the associated standard program uses and, if so, under what circumstances. Families and the public should have easy access to information about the state's NBS specimen disposition policy. Multidisciplinary input, including from consumers, should be solicited and thoughtfully considered in developing a NBS residual specimen disposition policy.

All state NBS programs should develop a well-defined strategy to educate healthcare professionals who provide patients with prenatal and postnatal care about NBS and the potential uses of residual NBS specimens.

Better public understanding and acceptance of state NBS policies on the possible storage and use of residual NBS specimens depend heavily on the involvement of healthcare providers. Studies validate the need for better physician education to meet the educational needs of the screening program. ${ }^{11,12}$ The role of the obstetrician as an educator in the NBS process has been defined, ${ }^{13}$ and the American College of Obstetricians and Gynecologists has published a position paper-American College of Obstetricians and Gynecologists Committee on Genetics Opin- 
ion - that encourages its members to become aware and involved in state NBS efforts. ${ }^{14}$ However, most obstetricians still do not seem to educate their patients about NBS. ${ }^{11,12}$ The strategy should include steps to inform and train healthcare professionals about the NBS system, the state's policy on the potential use of residual NBS specimens, and their educational responsibilities with respect to expectant parents and parents of newborns. Educational programs primarily should focus on prenatal care providers. Education of postnatal care providers should instruct them to follow-up on prenatal educational efforts and be cognizant of new parents who did not have access to prenatal care and, therefore, did not receive prior information about the NBS system.

All state NBS programs should create policies that are in compliance with federal research regulations, assure that parents are aware of these activities, and consider whether documentation of parents' wishes and willingness to participate are required. ${ }^{15}$

The state attorney general or other appropriate legal authority should review this process. The SACHDNC emphasizes that the use of residual NBS specimens for standard program uses are valid components of the public health NBS program and, therefore, do not require additional consent. Once the use of a residual NBS specimens moves beyond the state NBS mandate and related standard program uses, each state needs to consider whether separate or blanket consent/dissent processes for approved studies are required from parents, legal guardians, or individuals screened (on reaching the age of majority) for using residual NBS specimens.

All state NBS programs should work proactively to ensure that all families of newborns are educated about NBS as a part of prenatal and postnatal care.

As part of the educational process, all state NBS programs should maintain and distribute educationally and culturally appropriate information that includes basic information about the uses or potential uses of residual NBS specimens. Processes should be in place to evaluate the extent, timing, and parental comprehension of NBS education with a focus on educational program improvement. Although NBS educational programs should concentrate on the prenatal period, they also should be designed to reach parents who do not have access to those services and, therefore, may require in-hospital education about NBS. Educational materials should address potential uses of residual NBS specimens, long-term storage policies, options for parents regarding storage and use of specimens, and information on specimen stewardship.

The Secretary of HHS should help improve efforts to educate the public and healthcare providers about NBS and the retention and use of specimens.

Educational programs should be developed that take into account existing resources for the public on the importance of NBS and the potential uses of residual NBS specimens to generate population-based knowledge about health and disease. Educational materials directed to healthcare professionals and consumers with facts about potential uses of residual NBS specimens and other related issues should be developed. Administrative support and funding should be provided to the Health Resources and Services Administration,
Maternal and Child Health Bureau through grant awards to states for developing these programs and materials.

The Secretary of HHS should facilitate a national dialog among federal and state stakeholders about policies for the retention and use of residual NBS specimens, including model consent and dissent processes.

National guidance should be developed for consent and dissent for the secondary use of NBS specimens and mechanisms to ensure privacy and confidentiality, including methods for opting in or out of residual dried blood spot repositories and options for children whose specimens are stored once they reach the age of majority. In addition, data should be collected and analyzed nationally on the utility of any additional consent or dissent processes implemented relative to potential research uses of residual NBS specimens. The HHS Secretary should encourage states to defer making permanent policy changes that would result in prematurely destroying specimens until guidance is available for their consideration and use in establishing such policies. Administrative support and funding should be provided to the SACHDNC to facilitate this dialog and develop this guidance.

The Secretary of HHS should explore the utility and feasibility of establishing a voluntary national repository of residual dried blood specimens, in which parents may choose to participate.

The use of residual NBS specimens for test development and research has accelerated discovery and has resulted in direct public health benefits. ${ }^{16,17}$ For example, studies in Wisconsin and Massachusetts, which aimed to identify children with Severe Combined Immune Deficiency (SCID) (OMIM\#'s 102700, 602450, 611291, 601457, 300400, 600802, 608971, and 269840), also provided previously unavailable data, so that SACHDNC could make an evidence-based decision about whether to add SCID to the nationally recommended uniform NBS panel. ${ }^{17,18}$ SCID was recommended for addition to the uniform core screening panel in January 2010 and approved by the HHS Secretary in May 2010. So that these essential types of activities may continue, additional funding should be made available to the Centers for Disease Control and Prevention and the National Institutes of Health to draft policies and guidelines that address the support and maintenance of the repository, stewardship of the specimen collection (including access and retention policies), establishing oversight systems, and addressing legal and ethical issues, including state law variations.

\section{CONCLUSION}

As the NBS community first published guidance regarding the retention, storage, and use of residual NBS specimens, ${ }^{19}$ improvements in policy development among state NBS programs have occurred. Nevertheless, aspects of the current public policy environment, including differing or lacking state policies on the need for explicit consent (an opt-in approach to secondary use of residual dried blood specimens) or dissent (an opt-out approach to secondary use of residual dried blood specimens that presumes consent unless explicitly refused), ${ }^{20}$ potential uncertainty about authority over decision making with respect to residual NBS specimens in states without a well-defined policy, and minimal public awareness of NBS, send an unclear message to the public about the purpose of storage and use of 
residual NBS blood specimens. This has engendered public concern about the storage of residual NBS specimens even for standard NBS program uses.

In light of growing use of residual NBS specimens, and their potential secondary applications, proactive solutions should be envisaged to ensure proper public education, parental choice, including an informed process for consent or dissent, and protection of genetic privacy and confidentiality. ${ }^{21}$ All programs seeking to store residual NBS specimens should strive for public trust and transparency of operations and policies. Public health organizations should encourage open and informed dia$\log$ with the public as part of the screening process.

Because NBS is the only public health screening program that reaches the entire population of newborns in the United States, it is unique, and the policies governing it must be thoughtfully approached. The storage and use of residual blood specimens for nonstandard uses such as research may not be adequately addressed in current state laws or policies. Policies developed for the storage and use of residual dried blood specimens for research should not harm long-standing and highly effective state NBS programs, including their ability to store and use specimens for essential program activities. Rather, these policies should strengthen these well-established public health programs through increased public education and engagement. The SACHDNC believes that national guidance on the retention and use of residual NBS specimens would help states to navigate these complex issues. Understanding that policymakers need to weigh the benefits and costs of NBS, guidance should address the costs associated with the infrastructure for the storage and use of residual NBS specimens and the financing of the NBS system. Public confidence and trust must be sustained in all activities related to handling, retaining, and using residual dried blood spots.

[The extended version of this article is available as Supplemental Digital Content 1, http://links.lww.com/GIM/A168.]

\section{REFERENCES}

1. Consumers refers to the definition in the Newborn Screening American Health Information Community Detailed Use Case: "Members of the public that include patients as well as caregivers, patient advocates, surrogates, family members, emergency contacts, and other parties who may be acting for, or in support of, a patient receiving or potentially receiving healthcare services." American Health Information Community, Newborn Screening: AHIC Detailed Use Case. Washington, DC: U.S. Department of Health and
Human Services, Office of the National Coordinator for Health Information Technology, 2008.

2. Federal Register, 2010. Available at: http://www.federalregister.gov/articles/ 2010/04/26/2010-9625/secretarys-advisory-committee-on-heritable-disordersin-newborns-and-children. Accessed January 25, 2011.

3. Institute of Medicine, 2010. Available at: http://iom.edu/Activities/Research/ GenomicBasedResearch/2010-MAY-24.aspx. Accessed January 25, 2011.

4. SACHDNC, 2010. Available at: http://www.hrsa.gov/heritabledisorders committee/correspondence/HowellLettertoSebeliusOct132010.pdf. Accessed January 25,2011

5. Clinical and Laboratory Standards Institute (CLSI). Blood collection on filter paper for newborn screening programs; approved standard-fifth edition. CLSI document LA4-A5. Wayne, PA: Clinical and Laboratory Standards Institute, 2007.

6. McEwen JE, Reilly PR. Stored Guthrie cards as DNA banks. Am J Hum Genet 1994;55:196-200.

7. Annas GJ. Privacy rules for DNA databanks. JAMA 1993;270:2346-2350.

8. Therrell BL, Johnson A, Williams D. Status of newborn screening programs in the United States. Pediatrics 2006;117:212-252.

9. Scheck B. DNA data banking: A cautionary tale. Am J Hum Genet 1994; 54:931-933 [Editorial].

10. McEwen JE, Reilly PR. A review of state legislation on DNA forensic data banking. Am J Hum Genet 1994;54:941-958.

11. Hasegawa LE, Au SM, Matsumoto CA. The obstetrician's role in newborn metabolic screening: a physician survey. Hawaii Med $J$ 2005;64:239-243.

12. Faulkner LA, Feuchtbaum LB, Graham S, Bolstad JP, Cunningham GC. The newborn screening educational gap: what prenatal care providers do compared with what is expected. Am J Obstet Gynecol 2006;194:131-137.

13. Larsson A, Therrell BL. Newborn screening: the role of the obstetrician. Clin Obstet Gynecol 2002;45:697-710.

14. ACOG Committee Opinion Number 393 Newborn Screening. Obstet Gynecol 2007;110:1497-1500.

15. National Institutes of Health, Code of Federal Regulations, Protection of HumanSubjects,2005.Availableat:http://ohsr.od.nih.gov/guidelines/45cfr46. html. Accessed January 25, 2011.

16. Comeau AM. Newborn screening expansion: Massachusetts Research Models Encompass Public Health Service Responsibility. In: Knoppers BM, editor. Genomics and public health: socio-ethical and legal perspectives. Leiden: Martinus Nijhoff International (Brill), 2007:45-53.

17. Institute of Medicine (IOM). Challenges and opportunities in using residual newborn screening samples for translational research: workshop summary. Washington, DC: The National Academies Press, 2010.

18. Baker MW, Grossman WJ, Laessig RH, et al. Development of a routine newborn screening protocol for severe combined immunodeficiency. $J$ Allergy Clin Immunol 2009;124:522-527.

19. Therrell BL, Hannon WH, Pass KA, et al. Guidelines for the retention, storage, and use of residual dried blood spot samples after newborn screening analysis. Biochem Mol Med 1996;57:116-124.

20. Saunders B. Normative consent and opt-out organ donation. J Med Ethics 2010;36:84-87.

21. Kharaboyan L, Avard D, Knoppers BM. Storing newborn blood spots: modern controversies. J Law Med Ethics 2004;32:741-748. 